\title{
PARA
}

\section{UMA EXPLICAÇÃO \\ COGNITIVAMENTE \\ PLAUSÍVEL \\ DA CONJUNÇÃO \\ EM PORTUGUÊS}

\section{UNA EXPLICACIÓN COGNITIVAMENTE PLAUSIBLE DE LA CONJUNCIÓN EN PORTUGUÉS}

FOR A COGNITIVELY PLAUSIBLE EXPLANATION OF THE CONJUNCTION IN PORTUGUESE

Heronides Moura*

Giuseppe Varaschin**

Universidade Federal de Santa Catarina

\begin{abstract}
RESUMO: O objetivo deste artigo é propor as linhas gerais de um modelo teórico para explicar a conjunção "e" de um ponto de vista semântico, pragmático e cognitivo. Se a análise contextualista proposta por Robyn Carston (2002) puder ser defendida e se mostrar como a melhor opção diante dos problemas inerentes às demais abordagens, seguir-se-á que o processo pragmático primário que Recanati (2010) chama de "modulação" é uma realidade, ao menos neste caso, na composição semântica das línguas naturais. Isto é, ficará comprovada a existência de ao menos um caso em que fatores contextuais opcionais - aqueles que, ao contrário da indexicalidade, não são demandados pelas regras estritamente linguísticas - afetam o conteúdo proposicional dos enunciados.
\end{abstract}

PALAVRAS-CHAVE: Conjunção. Contextualismo. Pragmática.

RESUMEN El objetivo de este artículo es proponer las líneas generales de un modelo teórico para explicar la conjunción "e" del portugués desde un punto de vista semántico, pragmático y cognitivo. Si el análisis contextual propuesto por Robyn Carston (2002) se puede defender y si se muestra la mejor opción frente a los problemas inherentes a las demás vertientes, significa que el proceso pragmático primario al que Recanati (2010) se refiere como “modulación” es una realidad en este caso, en la composición semántica de las lenguas naturales. O sea, se comprobará la existencia de, por lo menos, un caso en el que factores contextuales opcionales -

\footnotetext{
*Professorda UFSC e pesquisadordo CNPQ. E-mail: heronides@uol.com.br. 
aquellos que difieren de la indexicalidad por no tener exigencias de reglas estrictamente lingüísticas - afectan el contenido proposicional de los enunciados.

PALABRAS CLAVE: Conjunción. Contextualismo. Pragmática.

ABSTRACT: The aim of this article is to generally propose a theoretical model to explain the conjunction "e" from a semantic, pragmatic, and cognitive point of view. If Robyn Carston's (2002) contextualist analysis can be defended and show itself as the best option before of the problems inherent to other approaches, the primary pragmatic process called by Recanati (2010) "modulation" is a reality, at least in this case, in the semantic composition of natural languages. In other words, the evidence of the existence of at least one case in which optional contextual factors - the ones that, contrary to indexicality, are not demanded by strictly linguistic rules - affect the propositional content of utterances.

KEYWORDS: Conjunction. Contextualism. Pragmatics.

\section{INTRODUÇÃO}

Há, à primeira vista, apenas uma reação teórica possível perante a percepção das diferenças entre os operadores da lógica proposicional e os seus análogos nas línguas naturais. Essa alternativa, de viés "semântico", consiste em postular, para cada interpretação intuitiva que um conectivo de uma língua assume, uma entrada lexical distinta. É nesse espírito que alguns manuais tradicionais de lógica ressaltavam que o símbolo $\vee$, o operador disjuntivo, não seria equivalente às suas contrapartes naturais, como, por exemplo, o "ou", pois estas últimas apresentariam uma ambiguidade entre um sentido "inclusivo" e outro "exclusivo ${ }^{1}$. A alternativa semântica parece pressupor que toda diferença na compreensão de um mesmo item linguístico em ocasiões diferentes deve proceder de uma diferença de significado lexical, configurando assim um caso de ambiguidade. Não haveria, no entanto, um outro modo de explicar a maneira como entendemos de formas diversas as mesmas palavras em contextos diferentes?

O nascimento da pragmática moderna foi, em larga medida, motivado pela intuição de uma segunda alternativa. Paul Grice (1981) notou alguns problemas fundamentais com essa abordagem semântica das diferentes leituras dos conectivos e propôs, como resposta, a inauguração de uma nova disciplina que estudasse o modo como inferimos, de um ato de fala, informações que não foram estritamente ditas. Surge aí o estudo das implicaturas conversacionais, e, para o caso dos conectivos em particular, das implicaturas conversacionais generalizadas. Um primeiro impasse, de caráter metodológico, com a proposta semântica diz respeito à proliferação desnecessária de significados. A fim de frear esse impulso pluralista, Grice formula o princípio da Navalha de Ockham Modificada (GRICE, 1989, p. 47), que nos orienta a não estipular significados distintos a menos que isso seja estritamente necessário.

Já aqui um estudo pormenorizado da conjunção começa a configurar uma empreitada particularmente promissora para uma abordagem pragmática e cognitiva, pois a multiplicação dos sentidos, modesta ainda no caso da disjunção, teria de ser realmente assombrosa para um conectivo como o "e”. Uma ínfima amostra extraída, em maior parte, do corpus NILC/São Carlos é suficiente para mostrar isso ${ }^{2}$ :

(1) O painel de plástico é simples e os bancos são forrados em tecido.

(2) O óleo foi colocado em tambores e levado para uma área nos fundos do Tebar.

(3) Paranaense, filha de um médico da Aeronáutica, começou a estudar arquitetura na Bahia e se formou no Rio.

(4) Guilherme foi atingido no pescoço e morreu sentado no banco de seu carro.

\footnotetext{
${ }^{1}$ Ver Copi et al. (2014, p. 310), para uma instância dessa linha argumentativa.

${ }^{2}$ Apenas os dois últimos exemplos foram extraídos de pesquisas no Google.
} 
(5) Ele me ofendeu e acabei dando o troco.

(6) Carvalinho é fã declarado e recorta tudo que a imprensa publica sobre a atriz.

(7) Estamos na contraditória situação de viver sob regime constitucional, das chamadas liberdades democráticas, e sermos governados de forma própria do autoritarismo.

(8) Ontem o grupo de Jorge Luiz convidou os jornalistas para entrar na favela e verificar os locais onde houve a troca de tiros.

(9) 3 anos atrás eu fui para Paris e visitei a Torre Eiffel.

(10) Sorria e o mundo sorri com você.

Esses casos sugeririam, em uma perspectiva puramente semântica, ambiguidades que vão muito além daquela atribuição de dois sentidos - um meramente verofuncional e simétrico como em (1), e outro de sequência temporal, assimétrico, como em (2) - que o próprio Grice (1981) imputara à Strawson (2011). Se assumíssemos como exigência para nossa teoria semântica a assimilação de todas as intuições dos falantes acerca das diversas relações expressáveis pela conjunção, teríamos que admitir, além desses dois sentidos, um sentido temporal distante, como em (3) - em oposição ao exemplo (2), no qual compreendemos que a sucessão entre os eventos é mais rápida -, um sentido causal instantâneo e de condição suficiente como em (4), um sentido causal, mas não de condição suficiente, como em (5), um sentido causal não temporal, como em (6), um sentido "contrastivo", como em (7), um sentido temporal de "finalidade" (equivalente à expressão "a fim de"), como em (8), um sentido de continência espacial e temporal, como em (9), e, por fim, um sentido de condicional, como em (10). É verdade que Cohen (1971) alega que sua versão da alternativa semântica, por não postular várias entradas lexicais distintas, mas apenas um conjunto de "traços" associados a um mesmo item lexical, não viola o princípio de economia recomendado por Grice. No entanto podemos concordar com Carston (2002) quando ela afirma que essa estratégia de se "esquivar" da navalha Ockham é falaciosa, pois tal princípio poderia ser reformulado em termos de uma restrição contra a proliferação de traços semânticos também.

O fato é que mesmo a nossa lista de ambiguidades poderia ser inesgotavelmente ampliada, de modo que passamos a duvidar se uma língua assim é passível de ser adquirida por um ser com uma mente limitada como a nossa. Posner (1980, p.188) levanta questão semelhante: "[...] como poderia um usuário da língua lidar com uma palavra com um número infinito de significados?". Uma entrada lexical com um número indefinido de traços (ou um número indefinido de entradas lexicais para uma mesma forma fonológica) parece ser uma noção um pouco esdrúxula e psicologicamente implausível. Ademais, como argumenta Recanati (2004, p. 134) partindo de um caso semelhante, parece que não temos aqui uma lista pré-estabelecida de sentidos discretos para a palavra, dentre os quais selecionamos, no contexto, aquele que é mais adequado - que é o que geralmente ocorre com expressões ambíguas -, e sim uma criação ou geração livre de sentidos ajustados à situação.

\section{OS PROBLEMAS DA ANÁLISE GRICEANA}

Essas e outras razões levaram Grice (1989) e seus discípulos (POSNER, 1980; LEVINSON, 1983) a aventar uma teoria que preserva a univocidade lógica da conjunção na semântica e que delega os acréscimos contextuais específicos ao nível das implicaturas. As diversas leituras da conjunção "e" seriam inferências pós-proposicionais que tomam como input o significado literal da expressão (que é meramente lógico em todos os casos) e a suposição de que o falante está agindo de acordo com o Princípio da Cooperação e as Máximas Conversacionais - aqui, em especial quarta submáxima do Modo ("seja ordenado"). Nas palavras de Levinson:

Podemos ver agora como o semanticista [...] não precisa reivindicar que há duas palavras 'e’ em português, uma significando simplesmente que ambas as sentenças da conjunção são verdadeiras, e a outra tendo o mesmo significado somado a uma noção de sequencialidade. Pois a sequencialidade, o sentido de 'e então', do 'e' [...] é simplesmente uma implicatura padronizada devida à quarta submáxima do Modo, que proporciona um 
revestimento pragmático sobre o conteúdo semântico do 'e’ sempre que as descrições de dois eventos que possam estar ordenados sequencialmente forem postas em conjunção. (LEVINSON, 1983, p. 108)

Mas essa solução também não está totalmente imune a problemas.

\subsection{QUAL O PRINCÍPIO GERADOR DAS IMPLICATURAS?}

O primeiro, e menos grave, diz respeito à suposta exclusividade da máxima do Modo como princípio gerador das implicaturas em questão. Está claro que um simples imperativo para que o falante "seja ordenado" e narre os eventos na sequência em que eles aconteceram não é suficiente para explicar boa parte das informações que extraímos dos exemplos (1)-(10). Primeiro, porque essa máxima só se aplica aos usos da conjunção em contextos narrativos, isto é, naqueles em que há alguma relação temporal implicada entre os eventos. Segundo, porque, como argumentam Sperber e Wilson (2010), mesmo em contextos narrativos, qualquer princípio que apele exclusivamente à iconicidade - como a máxima do Modo de Grice, a submáxima do tempo formulada por Harnish (1991) e o princípio de interpretação de discursos temporais defendido por Dowty (1986) - não dá respostas satisfatórias a dois dos principais desafios levantados pelos exemplos (1)-(10): o problema do intervalo e o problema da causalidade. A quarta submáxima do Modo aplicada aos usos da conjunção "e" em construções narrativas só dá conta de explicar como extraímos a noção de sequencialidade de um exemplo como (2), mas não nos propicia nenhum esclarecimento acerca de como compreendemos que os dois eventos descritos em (3) não estão separados pelo mesmo intervalo temporal que atribuímos àqueles em (4) - a máxima de Grice não bloquearia, por si só, a intepretação de (4) como "Guilherme foi atingido no pescoço e morreu sentado no banco do carro dez anos depois" - e, também não explica como, em (5) por exemplo, sobrepomos à representação sequencial uma representação causal (o falante deu "o troco" porque alguém o ofendeu, e não só depois de alguém o ter ofendido).

Digo que esse problema é o menos grave, pois ele foi prontamente percebido e facilmente solucionado por griceanos como Schmerling (1975), Posner (1980) e Levinson (1983, 2000). O que eles fizeram, grosso modo, foi simplesmente propor um novo conjunto de princípios que desse conta de explicar como chegamos às diversas interpretações da conjunção. A proposta de Levinson (2000) parece a defesa mais bem fundamentada da análise griceana. Ele argumenta que, devido a um descompasso intrínseco entre nossa imensa capacidade de processar informação e nossos limitados meios para transmitir essa informação, precisamos de certas estratégias que amplifiquem de um modo regular e padronizado aquilo que dizemos. Em outras palavras, porque, de um lado, o pensamento é rápido e a inferência é barata, e, de outro, a nossa capacidade de vocalização é lenta e custosa, é conveniente que tenhamos alguma heurística cognitiva que nos ajude a desenvolver inferencialmente conteúdos ricos e complexos a partir de estímulos linguísticos fragmentários e esquemáticos. Uma dessas heurísticas é a que ele chamou, em Levinson (1983), de Princípio da Informatividade. O que esse princípio afirma é que, quando nós expressamos algo de maneira "simples" ou "típica", tenderemos a supor que a situação que estamos descrevendo é igualmente simples e típica. Nas palavras do autor, "[...] o que é expressado de forma simples deve ter acontecido de forma estereotípica" (LEVINSON, 2000, p. 37).

Levinson aplica esse princípio de modo elegante à análise da conjunção. Para ele, sempre que um falante junta dois eventos com uma conjunção, o ouvinte está autorizado a supor "[...] as conexões temporais, causais e referenciais mais ricas possíveis entre as situações ou eventos descritos de acordo com o que é conhecido” (2000, p. 114). Em uma formulação mais simples, sua análise prediz que nós derivamos da enunciação de (1)-(10) uma implicatura em que está prevista uma relação prototípica entre as cenas anexadas pela conjunção, de acordo com scripts cognitivamente salientes. Por isso, o falante não precisa sempre explicitar exatamente qual a relação entre os eventos, podendo simplesmente juntá-los com a partícula genérica "e", confiando que o ouvinte derivará as implicaturas adequadas.

Não fica claro, contudo, como tal princípio pretende dar conta de casos para os quais, ao menos aparentemente, não temos nenhum script cognitivo prévio ${ }^{3}$, ou casos em que a suposta implicatura contradiz os nossos scripts disponíveis, como em uma situação em

\footnotetext{
${ }^{3}$ Carston (2002, p. 251) cita alguns exemplos: "Sally cozinhou alguns vegetais e começou a se sentir otimista." e "Bill foi ao analista e caiu em um bueiro." Se há algum script que é invocado na interpretação dessas sentenças, são scripts de natureza muito genérica. O mais plausível é que o simples fato de essas sentenças estarem colocando lado a lado eventos tão disparatados nos faça criar, de uma maneira ad hoc, um script em que os eventos estejam relacionados de alguma forma mais rica.
} 
que invertêssemos a ordem de (4) de modo a comunicar que Guilherme foi atingido no pescoço depois de morrer. Outra dificuldade com essa análise é que ela não parece ter como explicar a maciça preponderância de conjunções que, de fato, seguem a sequência icônica. Se tudo o que é necessário para chegar às interpretações de (1)-(10) são os scripts evocados pelo conteúdo literal dos enunciados, deveríamos esperar encontrar, em nosso corpus, um número significativo de sentenças em que o evento codificado pela primeira sentença deva ser compreendido como sendo posterior ao da segunda. Não encontramos nenhum caso assim. Em suma, a análise de Levinson (2000) parece falhar exatamente no ponto que conferia à análise - também insuficiente - de Grice (1989) certo grau de plausibilidade e poder explicativo. Um mero apelo irrestrito aos scripts, sem qualquer menção à iconicidade, não parece ser suficiente para explicar o modo como interpretamos diversamente a conjunção em seus vários contextos.

Além disso, esse apelo aos scripts cognitivos está, aos olhos de um cognitivista, à serviço de duas causas perdidas: (a) a exclusão de conhecimentos enciclopédicos da proposição e (b) a preservação de um núcleo lógico unívoco à conjunção (isto é, a ideia de que as línguas naturais exibem "funções de verdade"). São esses os defeitos mais fundamentais das análises de linhagem griceana, e tratarei, em sequência, de cada um deles.

\subsection{A INFLUÊNCIA DO CONTEXTO NA PROPOSIÇÃO}

O primeiro problema foi explicitado, sobretudo, nos trabalhos de Recanati $(1991 ; 2004 ; 2010)$. Ele argumenta, de um modo bastante convincente, que as conotações adicionais acrescentadas ao sentido verofuncional da conjunção não apresentam certas características fundamentais que gostaríamos de atribuir às implicaturas. A saber, elas não parecem ser calculadas inferencialmente a partir de uma proposição previamente expressa, e também não parecem estar excluídas do conteúdo proposicional dos enunciados que as carregam. Quanto ao primeiro ponto, parece ser artificial - ou simplesmente incorreto - dizer que, por exemplo, em (2), processamos antes uma proposição literal "neutra" em relação à ordem temporal dos eventos, e inferimos, a partir dela e de alguma máxima, uma segunda proposição temporalmente ordenada. Segundo o filósofo e linguista francês, a derivação de uma implicatura pressupõe a acessabilidade do que é dito, e, nos casos (1)-(10), nós simplesmente não temos acesso às proposições temporalmente neutras. Quanto ao segundo ponto, critérios que distinguem os aspectos da significação que são partes da proposição expressa, daqueles aspectos que são implicaturas - como o critério da independência funcional defendido por Carston (1991)e o critério do escopo, formulado inicialmente por Cohen (1971) e desenvolvido por Recanati (1991) - sugerem que as noções de causalidade e temporalidade presentes em um exemplo como (4) são partes da proposição, isto é, da cena mental representada pela sentença.

Veremos aqui apenas como o critério do escopo, tal qual formulado por Recanati (1991), prevê que algumas das informações extraídas dos exemplos (1)-(10) acabam entrando na proposição. O critério é enunciado, pelo filósofo francês, da seguinte forma: "um aspecto pragmaticamente determinado da significação é parte do que é dito (e, portanto, não é uma implicatura conversacional) se - e talvez somente se - ele entrar no escopo de operadores lógicos, como a negação e o condicional.” (RECANATI, 1991, p. 114). Vejamos as seguintes alterações de algumas das frases citadas acima:

( (2a) Não é verdade que o óleo foi colocado em tambores e levado para uma área nos fundos do Tebar.

( $\left.3^{a}\right)$ Ou ela começou a estudar arquitetura na Bahia e se formou no Rio, ou ela se formou no Rio e começou a estudar arquitetura na Bahia.

Em $\left(2^{\mathrm{a}}\right)$, a sequenciação temporal que coloca o evento em que o óleo é colocado nos tambores antes de eles serem levados a uma área nos fundos é parte do que é negado pelo operador natural "não é verdade que". Igualmente, a ordem particular em que os eventos ocorreram é precisamente o que varia nas duas orações unidas em ( $3^{a}$. Uma maneira de deixar isso mais claro é o seguinte exemplo, inspirado em Strawson (2011), que também explora a leitura temporal da conjunção:

(11) Não é verdade que Maria se casou e ficou grávida: o que aconteceu foi que ela ficou grávida e se casou!

Esse script ad hoc é o que vai motivar o entendimento da relação entre os estados de coisas narrados. O script aí não preexiste à interpretação, ele é um resultado de uma suposição icônica. 
Se a proposição extraída desse enunciado tomasse o sentido do "e" como puramente verofuncional - isto é, seu sentido mínimo -, seríamos obrigados a considerar (11) como uma autocontradição. A conjunção, no cálculo proposicional clássico, é uma operação comutativa, de modo que a mudança da ordem dos constituintes em (11) não resultaria em nenhuma diferença no conteúdo veiculado. A proposição mínima extraível de (11) tem a seguinte forma lógica (supondo que $\mathrm{I}(\mathrm{C})=\mathrm{Maria}$ se casou e $\mathrm{I}(\mathrm{G})=\mathrm{Maria}$ ficou grávida):

$\neg(\mathrm{C} \wedge \mathrm{G}) \wedge(\mathrm{G} \wedge \mathrm{C})$

Se construirmos uma tabela de verdade, constataremos que essa fórmula recebe o valor de verdade "falso" em todas as valorações: é, pois, uma contradição.

Todavia, supondo um contexto adequado, dificilmente interpretaríamos (11) dessa maneira, ou seja, com esse sentido mínimo, puramente semântico. O que geralmente entenderíamos é que alguém que profere essa sentença diz não ser verdade que Maria se casou antes de ficar grávida, mas sim que ela ficou grávida e depois (e, possivelmente, por causa disso) se casou. Ora, esta última proposição inclui a especificação temporal (e certa especificação causal) no escopo da negação.

Contudo, pode parecer que o princípio do escopo, tal qual formulado acima, seja um pouco arbitrário. Por que as implicaturas não poderiam entrar no escopo de operadores? Não parece haver, a priori, nenhuma razão para aceitar essa colocação. O argumento inicial de Cohen (1971), que foi quem utilizou primeiro esse tipo de exemplo para criticar a análise em termos de implicaturas, dependia da suposição de que seus opositores também aceitassem a verofucionalidade estrita dos outros operadores proposicionais, como a negação e o condicional. Como ele bem percebeu, diante de exemplos como $\left(2^{\mathrm{a}}\right),\left(3^{\mathrm{a}}\right)$ e (11), um analista de implicaturas precisaria ou sacrificar a verofuncionalidade da conjunção ou sacrificar a verofuncionalidade do outro operador, em cujo escopo entram as diversas informações adicionais. Ou a verdade da conjunção não dependeria somente dos valores de verdade de suas "subfórmulas imediatas", ou a verdade dos outros operadores não dependeria somente dos valores de verdade da conjunção. No entanto, especialmente para os casos das implicaturas incorporadas ao escopo de condicionais, esse argumento perdeu muito de sua força. Poucos autores, como é o caso ainda de Lepore e Cumming (2009), sustentam hoje em dia que os condicionais das línguas humanas sejam equivalentes à função de verdade $\supset$ da lógica proposicional. Já Gazdar (1979) havia proposto como solução para o desafio de Cohen, precisamente, abandonar a verofuncionalidade da implicação nas línguas naturais.

É motivado por isso que Recanati $(1991,2010)$ apresenta uma outra justificativa para o princípio do escopo, inspirado nos trabalhos Ansconbre e Ducrot (1978) sobre os fenômenos escalares. Essa nova fundamentação do critério não se aplica mais somente aos casos em que as supostas implicaturas entram no escopo de operadores proposicionais clássicos, mas em qualquer "operador" natural, seja ele modal, epistêmico ou deôntico. Uma sentença como $\left(2^{\mathrm{b}}\right)$ teria, portanto, uma implicatura entrando no escopo do operador epistêmico "deve":

(2b) Você deve colocar o óleo nos tambores e levá-lo para uma área nos fundos do Tebar.

Nesses casos não faz sentido ameaçar a abordagem griceana com a necessidade de a verofuncionalidade do operador mais externo, como faz Cohen (1971), já que o operador deôntico em questão não é verofuncional. O problema em dizer, ainda assim, que esse operador aceita uma implicatura como parte de seu escopo é, segundo o raciocínio de Recanati, o seguinte:

(a) as implicaturas conversacionais são consequências pragmáticas de um ato de dizer algo.

(b) um ato de dizer algo só pode ser realizado por meio de uma enunciação completa, e não por meio de uma cláusula não-asserida, como o antecedente de um condicional.

(c) logo, nenhuma implicatura pode ser gerada em um nível sublocucionário, i. e., no nível de uma cláusula não asserida, como o antecedente de um condicional.

(d) dizer que uma implicatura cai no escopo de um operador é dizer que ela é gerada em um nível sublocucionário [...]

(e) logo, nenhuma implicatura pode cair no escopo de um operador. (RECANATI, 1991, p. 114) 
A ideia aqui é a de que só podemos chegar às implicaturas depois do cômputo de um ato de fala completo, dado que a implicatura é precisamente algo que inferimos a partir do conteúdo de um ato de fala. Mas os antecedentes de condicionais, as proposições negadas ou mesmo as sentenças encaixadas depois de operadores como os deônticos e os epistêmicos não são nunca atos de fala completos: são partes de um ato de fala - fazem parte do nível "sublocucionário". Logo, nenhuma implicatura poderia surgir nesses níveis. Mas é precisamente isso que Grice (1989) preveria para $\left(2^{\mathrm{a}}\right),\left(2^{\mathrm{b}}\right),\left(3^{\mathrm{a}}\right)$ e $(11)$. As supostas implicaturas aí estão sujeitas às influências semânticas dos operadores. Os operadores em questão atuam sobre uma proposição que contém as informações temporais e causais. Portanto, essas informações pragmaticamente derivadas não são inferências a partir de um conteúdo de um ato de fala prévio: elas integram o próprio conteúdo do ato de fala. O argumento de Recanati nos mostra que, sendo assim, Grice deve estar equivocado. Ao contrário do que supunha o filósofo britânico, as informações causais e temporais evocadas pelo "e" entram na proposição.

Mas admitir que os diversos enriquecimentos da conjunção afetam a proposição não seria reincidir em uma alternativa semântica que já vimos ser falha? Essa constatação só reconduziria àquela posição que criticamos se admitíssemos como verdadeiro o pressuposto de que todo efeito sobre a proposição tem de ser um efeito semântico. Porém, não há nenhuma razão que nos obrigue a aceitar isso - e, pelo contrário, as considerações sobre como certas informações pragmaticamente derivadas podem entrar no escopo de operadores parecem ser uma boa razão para rejeitar essa suposição. No entanto, todas as maneiras de rejeitá-la implicam abandonar a ideia de que toda influência pragmática sobre a interpretação linguística tem de ser uma implicatura no sentido tradicional (estritamente inferencial e pós-proposicional). É esse abandono que define o que na filosofia da linguagem atual se chama de contextualismo (CAPPELEN; LEPORE, 2005). A análise dos acréscimos contextuais em (1)-(10) em termos de implicaturas não é mais a única alternativa pragmática disponível, e os bons argumentos griceanos contra a alternativa semântica não afetam essa nova abordagem. Ficamos, assim, com uma versão enriquecida do princípio da composicionalidade do significado, formulada, por Jackendoff, do seguinte modo:

A estrutura conceitual de uma sentença pode conter, além do conteúdo conceitual dos itens lexicais, outros materiais que não estão expressos lexicalmente, mas que precisam estar presentes na estrutura conceptual para [...] satisfazer aspectos pragmáticos do discurso ou do contexto extralinguístico. (JACKENDOFF, 1997, p. 49)

O conteúdo de uma sentença deixa de ser uma simples função do conteúdo convencionalmente associado a cada uma de suas partes e passa a poder incorporar os sentidos contextualmente ajustados em conformidade a princípios pragmáticos e cognitivos. Isso implica dizer que fatores contextuais e enciclopédicos podem intervir na proposição e na composição semântica.

Alguns autores como Gazdar (1979) e Posner (1980), a despeito de suas entusiasmadas adesões ao modelo de explicação de Grice, foram impelidos - especialmente pela consideração de que as diversas sugestões temporais e causais dos exemplos como (2)-(6) e (8) caem no escopo de operadores (negação, condicionais, modais, epistêmicos, etc.) - a admitir que, nesses casos, a implicatura acaba fazendo parte das condições de verdade ou das proposições expressas pelas sentenças. Ora, um dos critérios iniciais de Grice para definir as implicaturas em oposição ao conteúdo dito é precisamente que aquelas, ao contrário deste, estão excluídas das condições de verdade, precisamente porque a implicatura é calculada com base nessas condições de verdade.

\subsection{A SEMÂNTICA DA CONJUNÇÃO}

O segundo defeito oculto da análise griceana que mencionei antes é a pretensão de conservar uma semântica unívoca da conjunção nas línguas naturais como uma função de verdade. Levinson, que acolhe esse propósito, deixa bem claro o ideal que o anima:

[E]ssa simplificação da semântica não é apenas uma redução de problemas no léxico; ela também torna possível a adoção de uma semântica construída sobre princípios lógicos simples. Ela faz isso demonstrando que, assim que as implicações pragmáticas do tipo que chamaremos de implicaturas são levadas em conta, as diferenças aparentemente radicais entre a lógica e a língua natural parecem desaparecer. (LEVINSON, 1983, p. 100) 
Na medida em que cognitivistas rejeitam a noção referencialista e logicista de semântica (cf. Jackendoff (1992) e Ferrari (2011)) em favor de uma semântica representacional ou translacional (cf. Carston (2002) e Martin (1978)), é bastante conveniente que tentemos propor outra análise, uma semântica não verofuncional para a conjunção "e". O sentido lógico da conjunção será visto como um mero "epifenômeno" do seu sentido cognitivo fundamental (SEUREN, 1988).

Txurruka (2003) e Bar-Lev e Paclas (1980) são propostas interessante nesse sentido. Estes últimos, por exemplo, propuseram uma noção que eles chamaram de "comando semântico" para o sentido da conjunção. Segundo eles, um item lexical como o "e" codifica a especificação de que a segunda proposição, em uma sequência " $\mathrm{P}_{1}$ e $\mathrm{P}_{2}$ ", não poderia ser "anterior (causalmente ou temporalmente)" à primeira (p. 141). Essa análise, contudo, como bem percebe Carston (2002), apesar de fornecer uma boa descrição do contraste entre algumas sentenças coordenadas e suas contrapartes assindéticas, acaba fazendo previsões equivocadas para um caso como (12), também recolhido do CORPUS NILC (2016):

(12) É só ver quem está jogando e nasceu de janeiro de 1973 para cá.

O que ocorre aí, muito claramente, é que certas informações codificadas pelo tempo verbal acabam se sobrepondo ao modo pelo qual naturalmente interpretamos a conjunção (que é bem capturado pela noção de "comando semântico"). Entendemos, sem nenhum problema, que algumas pessoas nasceram antes de jogar. Mas se, de fato, a conjunção codificasse semanticamente uma instrução para que consideremos o segundo evento como não anterior ao segundo, (12) deveria soar como uma contradição, à maneira de $\left(12^{a}\right)$ :

$\left(12^{a}\right)$ É só ver quem está jogando e depois nasceu de janeiro de 1973 para cá.

Na nossa opinião, a noção de "comando semântico" parece ser uma boa generalização descritiva de casos típicos em que a conjunção agrega sentenças no aspecto perfectivo. Mas, como toda generalização descritiva, ela possui exceções que a tornam inadequadas para fornecer, verdadeiramente, uma explicação para o fenômeno.

Uma análise recente, e bastante sofisticada, que também descarta a ideia de que a conjunção nas línguas naturais desempenha o papel estrito de uma função de verdade é a tentativa de solução sintática oferecida por Bjorkman (2013). Ela propõe, essencialmente, uma semântica do "e" sensível ao contexto sintático, em particular, sensível aos tipos de constituintes que a conjunção toma como especificador e complemento. Bjorkman (2013) nota que, em sentenças encaixadas como (13), há um contraste entre os casos em que os elementos unidos pela conjunção são CPs (13a) e TPs (13b):

(13a) Robson disse que João riu e que Maria ficou brava.

(13b) Robson disse que João riu e Maria ficou brava.

Quando os constituintes unidos são CPs (13a), a interpretação temporal/causal assimétrica não surge. Ela só surge para constituintes "menores", isto é, no quadro gerativo adotado pela autora, constituintes mais "baixos" na hierarquia sintática, como TPs ou VPs (13b). Ela estende isso para sentenças não encaixadas como (2)-(6) e diz que, nesses casos, há uma ambiguidade estrutural. Cada uma dessas sentenças teria duas estruturas subjacentes possíveis, uma em que a conjunção junta CPs (responsável pela interpretação puramente lógica e simétrica), e outra, mais acessível, em que a conjunção junta TPs (responsável pela intepretação assimétrica). Em contexto, uma ou outra dessas interpretações pode ser cancelada, o que configuraria uma "desambiguação" da estrutura da sentença.

Há, contudo, alguns contraexemplos bastante fortes a essa análise. Não há espaço para mencionar todos, mas vejamos apenas uma sentença como (14):

(14) Robson disse que Maria é feliz e é gentil.

Nesse caso, apesar de a conjunção estar juntando o que supostamente são dois TPs ou VPs, não surge uma interpretação temporal. Parece, como a própria autora percebe quando tenta estender sua análise para a junção de NPs, que o surgimento de uma leitura 
assimétrica do "e" depende muito mais do tipo semântico dos conceitos que ele toma como argumento do que da categoria sintática dos constituintes que ele subcategoriza. A solução para o problema, de fato, não tem como vir exclusivamente da sintaxe.

Tanto a abordagem das implicaturas quanto essa alternativa sintática buscam preservar, de modos distintos, o princípio de uniformidade da interface sintaxe-semântica, que é um dos pilares do mainstream da linguística gerativa (JACKENDOFF; CULICOVER, 2005, p. 6). A primeira nega que a conjunção nos exemplos (1)-(10) exiba sentidos diferentes, dado que as sentenças instanciam formas semelhantes. A segunda acolhe nossa intuição de que, há, de fato, um contraste de sentido entre (1) e (2), por exemplo, e busca explicá-lo postulando duas estruturas subjacentes, cada uma correspondendo a um único significado. Mantémse, nos dois casos, a ideia de que uma forma está associada a um só sentido, e vice-versa. Os griceanos insistem na univocidade da contribuição da conjunção para a proposição a fim de preservar um ideal lógico de composição semântica (segundo o qual o sentido que uma expressão incorpora na proposição é sempre o sentido que ela possui independentemente, em virtude de regras lexicais simples), a alternativa sintática aproxima a composição semântica de nossas intuições, mas o faz ao preço de uma complicação excessiva da sintaxe.

Outra dificuldade óbvia com a solução sintática e com alternativas semânticas como a de Bar-Lev e Paclas (1980) ou a de Txurruca (2003) - e que, na verdade, deve servir de alerta para a tentativa de elaborar uma semântica lexical para o "e" - é que elas não chegam nem perto de explicar todas as interpretações que a conjunção "e" pode assumir. Elas explicam apenas como pode haver um contraste entre casos simétricos e assimétricos. Entretanto, especificações de intervalos temporais específicos e de ligações causais variadas ficam totalmente sem explicação (isso para não falar de propriedades retóricas e discursivas, como a que vimos em (7)). Uma solução global para o problema deve envolver uma reconciliação entre semântica e pragmática.

Seja qual for a semântica que formos propor, ela não pode cair no engodo de querer dar conta de todos os casos. Ela deve deixar um bom espaço aberto para as possibilidades de ajuste pragmático. Cremos ser legítimo o apelo griceano para tornar a semântica da conjunção o mais "mínima" e "unívoca" quanto possível. Discordamos apenas da separação pressuposta entre composição semântica e pragmática e do modo como a semântica da conjunção nas línguas naturais foi simplesmente "transplantada", sem quaisquer ressalvas e adaptações, da semântica do operador proposicional $\wedge$ da lógica.

\section{UMA SEMÂNTICA CONCEITUAL PARA A CONJUNÇÃO}

A proposta esboçada aqui se baseia, sobretudo, nos cognitivistas Kitis (2000) e Croft (2001). A ideia de fundo, comum a esses dois autores, é que a estrutura conceitual que subjaz ao entendimento da conjunção envolve a integração gestáltica de dois Eventos em um "todo" unificado. Kitis (2000) fala da integração de duas cenas em um mesmo frame, e Croft (2001) da unificação de duas entidades em uma figura complexa, pressupondo um "denominador comum”, isto é, uma semelhança entre ambas. A formalização que empregaremos, por sua vez, deriva do trabalho de Jackendoff $(1983,1992)$ em semântica conceitual.

Concordaremos com os semanticistas formais em dizer que a conjunção "e" atua, semanticamente, como uma função comutativa. No entanto, ela não é, como é para eles, uma função que mapeia os valores semânticos das cláusulas que ela une (seus valores de verdade) em um outro valor de verdade, mas sim uma função que toma como argumento duas representações (constituintes conceptuais) e gera, como valor, uma representação (constituinte conceptual) maior, que contém as representações anteriores - daí a pertinência da observação cognitivista de que as entidades amalgamadas integram um "todo". Cada conceito que a funçãoconjunção toma como argumento corresponderá ao valor semântico de um constituinte sintático que a conjunção "e" subcategoriza. Esquematicamente, teríamos algo como:

SemConj: $\left[\mathrm{e}\left(\left[\mathrm{y}_{1}\right],\left[\mathrm{y}_{2}\right]\right)\right]$

Onde "y" vale para qualquer conceito sentencial (isto é, para qualquer combinação de conceitos lexicais que atinja um nível plenamente proposicional) denotado por uma das sentenças unidas pela conjunção. Note-se que a estrutura interna de um dos " $y$ " pode conter também uma conjunção, o que caracteriza SemConj como uma função recursiva. 
Um dos postulados de Jackendoff (1992) é que cada constituinte conceitual se encaixa em uma categoria ontológica (Coisa, Evento, Estado, Lugar, Caminho, Propriedade ou Quantidade). Como estamos buscando aqui prioritariamente uma semântica da conjunção entre sentenças completas, sem nos comprometermos com o fato de essa análise poder ou não ser estendida para os casos de conjunções entre constituintes subsentenciais (como NPs ou APs, por exemplo), parece-nos que o resultado da aplicação de SemConj será sempre uma proposição igualmente completa. Jackendoff não afirma isso em seus textos, mas é intuitivamente plausível supor que proposições (ou conceitos sentenciais) sempre se enquadraram em uma de duas categorias ontológicas possíveis: Estados ou Eventos. A categoria ontológica em que se enquadrará uma dada instância de SemConj dependerá não somente da categoria dos " $y$ ", mas também do tipo de relação entre esses constituintes que será contextualmente especificada. Se $y_{1}$ e $y_{2}$, por exemplo, forem dois Eventos onde um sucede temporalmente ao outro, como em (2), poderemos garantir que o constituinte em que a proposição como um todo se enquadra será também um Evento.

Uma generalização inicial que podemos fazer com base nesse tipo de análise é que certas configurações particulares de categorias ontológicas parecem facultar alguns tipos de interpretações. Uma interpretação temporal, por exemplo, só pode se dar entre constituintes de tipo " $y$ " que se enquadrarem na categoria de Evento. Cognitivamente, nós só compreendemos que duas coisas podem suceder temporalmente se forem processos que envolvem uma noção de dinamicidade - ou seja, Eventos, em oposição aos Estados, que são tidos como estáticos (COMRIE, 1976). Esse é, indiscutivelmente, o caso de (2)-(5) e (8) - nos quais, além de os verbos denotarem Eventos, os Eventos são conceitualizados de acordo com o aspecto perfectivo ${ }^{4}$. Quanto à causalidade, contrariamente, nós a concebemos como possível de se dar entre um Estado e um Evento - como ocorre em (6), onde temos, primeiro, a especificação de um Estado representado como "atemporal", e, em seguida, um padrão de ação motivado por esse Estado - ou mesmo entre dois Estados (p. ex. "João é rico e consegue comprar várias coisas”). A interpretação condicional que ocorre em (10) pode ser analisada também como um tipo específico de relação entre Eventos, como sugere Bjorkman (2013).

A leitura condicional vem justamente desse caráter esquemático, da ideia de que, se um Evento sempre está relacionado a outro, se um ocorrer, o outro naturalmente ocorrerá também. Nossa análise também acomoda bem casos aparentemente problemáticos como a interpretação adversativa em (7). Como já havia mostrado Kitis (2000), o efeito de "negação de expectativa” que surge nesse tipo de exemplo vem justamente do fato de que estamos unindo, em uma única situação maior (ela diria, em um único frame), duas situações que cremos ser incompatíveis, isto é, situações que contradizem algum script cognitivo que temos armazenado na memória.

\section{CONCLUSÃO: E OS MECANISMOS PRAGMÁTICOS?}

Podemos aceitar que especificações dessa ordem entrem na semântica da conjunção, desde que se entenda que elas não são suficientes para determinar a intepretação que a conjunção vai assumir dadas as categorias ontológicas de seus argumentos semânticos, mas apenas para fixar, esquematicamente, os tipos de interpretação que ela pode receber. O que determinará, para um dado uso, qual interpretação a conjunção vai definitivamente assumir são princípios cognitivos gerais que atuam na interpretação de estímulos linguísticos. Esses princípios são sensíveis ao contexto, que, portanto, como vimos, acaba intervindo no processo de composição semântica, configurando aquilo que Jackendoff (1997) chama de composicionalidade enriquecida. A informação, em (4), de que foi depois e em resultado de ter sido atingido no pescoço que Guilherme morreu é incorporada à proposição no processo de composição semântica, embora não seja codificada por nenhum item lexical pronunciado na sentença. Concluímos, por conta de argumentos como o do escopo, que essas e outras informações semelhantes eram casos de influência do contexto na proposição. Como se dá essa influência do contexto? Cremos que a função representada em SemConj pode passar por um processo de modulação, formalmente descrito por Recanati (2010), no qual uma relação mais rica entre os elementos “y” pode ser especificada, como ocorre nos vários tipos de relações temporais e causais que notamos em (1)-(10). Teríamos, portanto, algo assim:

\footnotetext{
${ }^{4}$ A conceitualização dos Eventos no perfectivo, embora favoreça interpretações assimétricas, não parece ser absolutamente necessária. Em uma sentença no aspecto habitual, isto é, imperfectivo, podemos ter a mesma ideia de sequência temporal e relação causal, como em "João corre e cai”.
} 
Modulação de SemConj: $\left[e\left(\left[y_{1}\right],\left[y_{2}\right]\right)\right] \rightarrow$ processos pragmáticos $\rightarrow\left[\operatorname{ex}\left(\left[\mathrm{y}_{1}\right],\left[\mathrm{y}_{2}\right]\right)\right]$

Onde "x" é uma variável para relações factuais de certo tipo (o conjunto preciso de relações que podemos expressar usando a conjunção deverá ser determinado em pesquisas vindouras). Sabemos, a partir de (1)-(10), que vários tipos de relações causais, temporais e discursivas podem preencher o valor desse " $x$ ". (No entanto, há, notavelmente, alguns tipos de relações que não podem ser valor de "x". Bar Lev e Paclas (1980), por exemplo, argumentam que a relações explicativas não podem se dar entre eventos unidos com a conjunção.)

A modulação é uma descrição precisa do tipo de ligação forma/sentido com que ficamos depois de abandonar o princípio da uniformidade da interface entre sintaxe e semântica. Recanati (2010) define-a como um processo pragmático primário (isto é: anterior à identificação completa da proposição) e opcional. O enriquecimento da conjunção é um processo pragmático, pois o tipo de informação de que ele depende requer acesso ao conhecimento enciclopédico e a hipóteses sobre a intenção informativa do falante. É um processo primário pois, como vimos, as informações causais e temporais comunicadas pela conjunção têm de ser computadas antes do cálculo da proposição completa, dado que elas passam a integrar a proposição. Já o caráter opcional desses processos deve ficar claro a partir de um exemplo como (1), no qual a conjunção, de fato, não comunica nada além da simples união de dois estados de coisas. Não parece ser obrigatório que uma relação mais rica seja sempre dada. Além disso, como Grice (1981) já havia notado, mesmo nos exemplos para os quais provemos usualmente relações mais informativas, como (2)-(10), parece que há sempre a possibilidade de cancelar tais informações, tanto explicitamente, quanto contextualmente.

Essas são, no entanto, apenas algumas propriedades formais dos tipos de informações que extraímos dos usos da conjunção. Outra pergunta diz respeito ao tipo de princípio pragmático e cognitivo que determina qual interpretação a conjunção assumirá em uma dada situação. Os mecanismos específicos que guiam a construção de um sentido no contexto podem, a nosso ver, se pautar por uma meta de preservar a relevância da mensagem. A noção de relevância, tal qual formulada na pragmática cognitiva de Sperber e Wilson (1995), parece subsumir tanto a noção Griceana de iconicidade - pois sequências icônicas são mais "fáceis" de processar (cf. CARSTON, 2002) - quanto a ideia de conformidade a scripts cognitivos e ao conhecimento enciclopédico, sugerida por Levinson (2000) - pois a relevância é medida, não só pelo esforço de processamento de um estímulo, mas também pelo efeito que ele provoca nas nossas crenças prévias a respeito do mundo. Nossa mente tenderá a interpretar relações mais ricas entre as proposições, pois isso será quase sempre necessário para garantir a relevância do ato de juntar dois Eventos ou Estados em um só Evento ou Estado. Uma interpretação enriquecida de acordo com nossos scripts enciclopédicos mais salientes nos propicia "um fluxo natural de efeitos [cognitivos]" (CARSTON, 2002, p. 227), que contribuem com a relevância da interpretação a um baixo custo, dado que os scripts invocados são, precisamente, salientes e facilmente recuperáveis da memória. Fica como um tema para exploração futura ver os detalhes de como a semântica que elaboramos aqui interage especificamente com esse mecanismo pragmático para a geração das várias interpretações da conjunção.

\section{REFERÊNCIAS}

ANSCOMBRE, J. C.; DUCROT, O. Echelles argumentatives, echelles implicatives et lois de discours. Semantikos, v. 2, p. 43-67, 1978.

BAR-LEV, Z; PACLAS, A. Semantic command over pragmatic priority. Lingua, v. 51, n. 1, p. 137-146, 1980.

BJORKMAN, B. M. A Syntactic correlate of a semantic asymmetries in clausal coordination, 2013. Disponível em: $<$ http://individual.utoronto.ca/bjorkman/papers/Bjorkman\%20(2013)\%20Syntactic\%20Correlates\%20[NELS\%2041].pdf>. Acesso em: 13 maio 2015. 
CAPPELEN, Herman; LEPORE, Ernie. Insensitive semantics: a defense of semantic minimalism and speech act pluralism. Malden: Blackwell Publishing, 2005.

CARSTON, R. Implicature, Explicature and Truth-Theoretic Semantics. In: DAVIS, Steven (Ed.). Pragmatics: a reader. New York: Oxford University Press, 1991.p. 33-51.

Thoughts and utterances: the pragmatics of explicit communication. Malden: Blackwell Publishing, 2002.

COHEN, J. Some remarks on Grice's views about the logical particles of natural language. In: BAR-HILLEL (Ed.). Pragmatics of natural languages. Dordrecht: Reidel, 1971.p. 50-68.

COMRIE, B. Aspect. Cambridge: Cambridge University Press, 1976.

COPI, I.; COHEN, C.; McMAHON, K. Introduction to logic. Harlow: Pearson, 2014.

CROFT, W. Radical construction grammar: syntactic theory in typological perspective. Oxford: Oxford University Press, 2001. Studies in the way of words. Cambridge: Harvard University Press, 1989.

DOWTY, D. The effects of aspectual class on the temporal structure of discourse: semantics or pragmatics? Linguistics and Philosophy. v. 9, n.1, p. 37-61, 1986.

FERRARI, L. Introdução à linguística cognitiva. São Paulo: Contexto, 2011.

GAZDAR, G. Pragmatics: Implicature, presupposition and logical form. New York: Academic Press, 1979.

GRICE, P. Presupposition and conversational implicature. In: COLE, Peter. Radical pragmatics. New York: Academic Press, 1981. p. 183-198.

Studies in the way of words. Cambridge: Harvard University Press, 1989.

HARNISH, M. Logical form and implicature. In: DAVIS, Steven (Ed.). Pragmatics: a reader. New York: Oxford University Press, 1991.

JACKENDOFF, R. The architecture of the language faculty. Cambridge: MIT Press, 1997.

What is a Concept that a Person May Grasp It? In: . Languages of the mind. Cambridge: MIT Press, 1992. p. 21-52. Semantics and cognition. Cambridge: MIT Press, 1983.

JACKENDOFF. R.; CULICOVER, P.W. Simpler syntax. Oxford: Oxford University Press, 2005.

LEVINSON, S. Pragmatics. New York: Cambridge University Press, 1983.

. Presumptive meanings: the theory of generalized conversational implicature. Cambridge: MIT Press, 2000.

KITIS, E. Connectives and frame theory. Pragmatics \& Cognition. v.8, n.2, p. 357-409, 2000. 
LEPORE, E; CUMMING, S. Meaning and argument. Chichester: Wiley-Blackwell, 2009.

MARTIN, E. J. The psychological unreality of quantificational semantics. In: SAVAGE, C. W. (Ed.). Minnesota studies in the philosophy of science. Minneapolis: University of Minnesota Press, 1978. p. 165-181.

CORPUS NILC. Disponível em: <http://www.linguateca.pt/acesso/corpus.php?corpus=SAOCARLOS>. Acesso em: 12 jan. 2016.

POSNER, R. Semantics and pragmatics of sentence connectives in natural languages. In: SEARLE, J; KIEFER, F.; BIERSWISCH, M. (Ed.). Speech act theory and pragmatics. Boston: Reidel, 1980. p. 169-203.

RECANATI, F. The pragmatics of what is said. In: DAVIS, S. (Ed.). Pragmatics: a reader. New York: Oxford University Press, 1991. Literal meaning. New York: Cambridge University Press, 2004.

Truth-conditional pragmatics. New York: Oxford University Press, 2010.

SCHMERLING, S. F. Assymetric conjunction and rules of conversation. In: COLE, P.; MORGAN, J. L. Syntax and semantics v. 3 : speech acts. Orlando: Academic Press, 1975, p. 211-231.

SEUREN, P. Pressuposition and negation. Journal of Semantics, v. 6, n. 1, p. 175-226, 1988.

SPERBER, D.; WILSON, D. Meaning and relevance. New York: Cambridge University Press, 2012.

Relevance: communication and cognition. Cambridge: Blackwell, 1995.

STRAWSON, P. Introduction to logical theory. New York: Routledge, 2011.

TXURRUKA, I. G. The natural language conjunction 'and'. Linguistics and Philsophy. v. 26, n. 1, p. 255-285, 2003. 